\title{
El Hábeas Corpus y sus clases como garantía jurisdiccional en la legislación ecuatoriana
}

\section{Habeas Corpus and its classes as a jurisdictional guarantee in Ecuadorian legislation}

\author{
Oswaldo Liber Andrade-Salazar \\ us.oswaldoandrade@uniandes.edu.ec \\ Universidad Regional Autónoma de los Andes, Santo Domingo \\ Ecuador \\ https://orcid.org/0000-0002-5851-0551 \\ César Hugo Tinajero-Vacas \\ ds.cesarhtv57@uniandes.edu.ec \\ Universidad Regional Autónoma de los Andes, Santo Domingo \\ Ecuador \\ https://orcid.org/0000-0001-7891-4396
}

Recepción: 15 de septiembre 2021

Revisado: 25 octubre 2021

Aprobación: 15 de noviembre 2021

Publicación: 01 de diciembre 2021 


\section{Estimado Editor (a):}

En el marco del sistema de justicia constitucional ecuatoriano encontramos que existe una variedad de garantías jurisdiccionales encaminadas a la protección de derechos, entre las que resalta, por su importancia, la acción constitucional de Hábeas Corpus, la cual es la medida por excelencia para la tutela del derecho a la libertad de las personas, siempre y cuando la privación de libertad reúna ciertas circunstancias establecidas en la Constitución y en la Ley.

Es así que encontramos en nuestra Carta Magna, en la sección tercera de las Garantías Jurisdiccionales, en el artículo 89, la acción constitucional de Hábeas Corpus, la cual en su redacción manifiesta que esta acción tiende a recuperar la libertad de las personas que hayan sido menoscabas de ella de forma ilegal, arbitraria e ilegítima, ya sea por orden de autoridad pública o por un particular; además, garantiza la protección del derecho a la vida y la integridad física de las personas privadas de la libertad. (Constitución de la República del Ecuador, 2008)

En la Ley de la materia, en el artículo 43, refiere al objeto de esta acción, señalando que "La acción de hábeas corpus tiene por objeto proteger la libertad, la vida, la integridad física y otros derechos conexos de la persona privada o restringida de libertad (...)" (Ley Orgánica de Garantías Jurisdiccionales y Control Constitucional, 2009)

Así mismo, los siguientes autores, describen a esta garantía como señalan a continuación:

La institución del habeas corpus permite evitar arrestos y detenciones arbitrarias, asegurando los derechos básicos de ser escuchado por la justicia y saber de qué se le acusa. También puede decirse que tutela los derechos fundamentales derivados de la vida y la libertad frente a cualquier acto u omisión de cualquier autoridad, funcionario o persona que pueda vulnerar dichos derechos. (Valarezo Álvarez, M. J., Coronel Abarca, D. F., \& Durán Ocampo, A. R., 2019, p.471)

En nuestro ordenamiento jurídico, encontramos al Habeas Corpus señalado en dos cuerpos normativos, el primero de índole Constitucional como nuestra Carta Política; y, la segunda de índole legal como la Ley Orgánica de Garantías Jurisdiccionales y 
Control Constitucional (en adelante LOGJCC), ambas en su contexto normativo hacen referencia a ciertas clasificaciones que la doctrina nos ha señalado, sin embargo, ignora de igual forma la existencia de más tipologías o clases que giran en torno a esta garantía.

Notablemente sobresale con mayor ímpetu en nuestra legislación lo que dogmáticamente se conoce como Habeas Corpus reparador, considerado como el aspecto clásico o tradicional de esta garantía, sin embargo, hay que resaltar que, la misma doctrina, el derecho comparado; y, el Sistema Interamericano de Derechos Humanos por medio de precedentes jurisprudenciales y opiniones consultivas, han sido enfáticos en señalar la existencia de diversas clases del Habeas Corpus y el alcance que esta garantía genera.

Así mismo, la Corte Constitucional del Ecuador, en reiteradas ocasiones, ha definido a estos tres aspectos, en primer lugar, dentro de la sentencia No. 207-11-JH/20 ha señalado que una privación de libertad se considera -ilegal- cuando contraría a los mandatos expresos contemplados en el ordenamiento jurídico, misma que debe ser analizada desde el aspecto material y formal, es decir, que la detención debe realizarse en juicioso cumplimiento de las circunstancias establecidas en la Ley; y, con el cumplimiento del procedimiento establecido. (SENTENCIA No. 207-11-JH / 20, 2020).

Además, la Corte ha manifestado, dentro de la sentencia 247-17-SEP-CC, que una privación de libertad es -arbitraria- cuando se considera ordenada y ejecutada sin otro fundamento más allá que la voluntad o capricho de la persona o autoridad que lo efectúa. De igual forma, dentro de la misma sentencia, la Corte manifiesta que se considera una privación de libertad como -ilegítima- cuando es ordenada y ejecutada por quien su potestad no le permite realizarlo, es decir, resulta incompetente para expedir órdenes privativas de libertad. (SENTENCIA N. ${ }^{\circ}$ 247-17-SEP-CC, 2017) Respecto a la actualidad de la problemática que gira en torno al Hábeas Corpus, es imperante destacar que, si bien es cierto esta garantía es una institución jurídica antigua, el estudio que se le ha dado dogmáticamente ha arrojado, en tiempos contemporáneos, una tipología o clasificación que es objeto de análisis para su 
aplicación en la legislación ecuatoriana. En este sentido, la importancia sobre el estudio de las clases de Hábeas Corpus y su aplicación en el Ecuador radica principalmente porque por su naturaleza, esta garantía está direccionada a la protección de derechos constitucionales en específico, como la libertad, vida e integridad física, además de que, con el fortalecimiento del alcance de las clases de Hábeas Corpus y su aplicación en la legislación ecuatoriana, se controlará el ejercicio del poder punitivo del Estado que en varias ocasiones ha sido protagonista de actos u omisiones vulneratorios a la libertad; y, demás derechos relacionados a éste.

En este orden de ideas, es menester indicar que, debido a las necesidades que han acaecido dentro de la casuística constitucional, dentro de los registros de la Corte Constitucional del Ecuador, a partir del año 2019, se identifica en la Sala de Selección un total de treinta y cinco casos que en su contexto refiere a los Hábeas Corpus Correctivo, Reparador, Preventivo, Innovativo; y, Traslativo, de los cuales en la actualidad no se ha desarrollado un criterio jurisprudencial amplio y que abarque de manera integral a estas clases de Hábeas Corpus, conllevando a la necesidad de realizar un estudio respecto de la aplicación y alcance de esta garantía en todo el sentido de su clasificación.

De igual forma, con el acontecer del ejercicio de las funciones de la actual Corte Constitucional, se evidencian desde el año 2019, un total de ocho sentencias muy dispersas que refieren sobre el Hábeas Corpus Reparador y Correctivo, sin embargo, no se explica a profundidad los lineamientos de aplicación del resto de clases de Hábeas Corpus. En lo que concierne al aspecto normativo, es inexorable destacar la ausencia de preceptos tanto constitucionales y legales que abarquen de manera integral las clases de Hábeas Corpus, considerando su alcance y aplicación en el Ecuador. Así mismo, se aprecia en menor proporción otras clases de Hábeas Corpus, las cuales son producto de la casuística, como el Preventivo, del cual no se tiene lineamientos de aplicación claras que nos permitan saber cuándo es correcto o no plantear esta clase de Hábeas Corpus, de igual forma, tenemos el Innovativo, cuyas causas, en su totalidad fueron negadas so pretexto de que los accionantes ya habían 
recuperado su libertad, ignorando por completo la naturaleza y objeto de esta clase de Hábeas Corpus.

Otra clase de esta acción es el Traslativo, del cual se puede discutir que, dentro de las dos causas planteadas, al momento de resolver, los Juzgadores no tienen claros los lineamientos de su aplicación, permitiendo que los accionantes se encuentren indebidamente privados de su libertad por demoras burocráticas injustificadas, situación que se evidencia en demasía dentro de los Centros de Rehabilitación Social, los cuales, no cuentan con un proceso ágil y eficiente para liberar a las personas que cuentan con la orden de libertad emitida por la autoridad competente, contraviniendo con norma expresa contemplada en la Constitución donde ordena que sin excepción alguna la persona detenida recobrará inmediatamente su libertad en los casos que amerite.

En este orden de ideas, también acciones de Hábeas Corpus que refieren al Reparador, de los cuales se discute la procedencia del mismo cuando existe una privación de libertad ilegal, arbitraria e ilegítima, en este punto, me parece interesante que esta clase se propone generalmente cuando proviene de un proceso penal, más que todo cuando los accionantes alegan vulneración del derecho a la libertad en cuestiones que refiere a las garantías básicas del debido proceso. Dentro de este marco, me parece novedoso realizar un análisis respecto al Hábeas Corpus planteado a favor de un animal como sujeto de derechos, a mi criterio, considero que este caso no debe ser enmarcado dentro de esta clase de Hábeas Corpus -reparador-más bien debe ser considerado dentro de una nueva clasificación, que debe fortalecerse y desarrollarse tanto desde la doctrina, jurisprudencia y la Ley.

Los investigadores estiman, necesario que la Corte Constitucional, como máximo órgano de control e interpretación de esta materia, emita en un solo precedente jurisprudencial los lineamientos y estándares de aplicación de forma detallada e integra de cada una de las clases de Hábeas Corpus que actualmente se encuentran en la Sala de Selección de la Corte, ampliando su rango de análisis más allá de los casos sub judice planteados, incluso me atrevo a señalar que la Corte podría realizar un análisis expansivo que abarque a todas las clases de Hábeas Corpus que nos 
señala la doctrina, con el fin de tener ya establecidos los lineamientos del resto de clases que se puedan presentar en un futuro dentro del devenir casuístico.

Lo manifestado en el párrafo que antecede se fundamenta sobre la base del artículo 2, numeral tercero, de la LOGJCC; en concordancia con el artículo 11, numeral octavo, de la Constitución del Ecuador, donde refiere al principio de progresividad y ampliación del análisis interpretativo por parte de la Corte Constitucional, permitiendo que este órgano emita jurisprudencia de carácter vinculante donde genere, garantice y reconozca las condiciones necesarias para el ejercicio de los derechos contenidos en la Constitución.

Para culminar, otro de los puntos a discutir es la necesidad de que exista una regulación legal o constitucional donde se exprese taxativamente las clases de Hábeas Corpus, a mi criterio no es necesario ningún tipo de reforma tanto en la Ley ni en la Constitución, porque es suficiente con el análisis jurisprudencial que la Corte nos pueda brindar, considerando que el parámetro hermenéutico que se pueda realizar es una interpretación del texto constitucional como tal; además, que permite la aplicación del bloque de constitucionalidad donde los derechos y garantías establecidos en la Constitución y en los instrumentos internacionales de derechos humanos son de directa e inmediata aplicación.

\section{FINANCIAMIENTO}

No monetario.

\section{AGRADECIMIENTO}

A la Universidad Regional Autónoma de los Andes, Santo Domingo, por motivar el desarrollo de la Investigación.

\section{REFERENCIAS CONSULTADAS}

Asamblea Nacional Constituyente de la República del Ecuador, (2008). Constitución de la República del Ecuador. [Constitution of the Republic of Ecuador]. Montecristi. Registro Oficial 449 de 20-oct-2008. Recuperado de https://n9.cl/sia 
Asamblea Nacional del Ecuador. (2009). Ley Orgánica de Garantías Jurisdiccionales y Control Constitucional. [Organic Law on Jurisdictional Guarantees and Constitutional Control]. Registro Oficial No. 52. Quito, Pichincha, Ecuador. Recuperado de: https://n9.cl/su7v

Corte Constitucional del Ecuador. (2020). Sentencia No. 207-11-JH / 20, CASO No. 207-11-JH. (El Pleno de la Corte Constitucional del Ecuador - 22 de julio de 2020).[ Judgment No. 207-11-JH / 20]. Recuperado de: https://n9.cl/qpt5k

Corte Constitucional del Ecuador. (2017).Sentencia N. ${ }^{\circ}$ 247-17-SEP-CC, Caso N. ${ }^{\circ}$ 0012-12-EP.[Judgment No. 247-17-SEP-CC]. (Pleno de la Corte Constitucional del Ecuador 09 de agosto de 2017). Recuperdo de: https://n9.cl/fh1cl

Corte Interamericana de Derechos Humanos. (1987). Opinión Consultiva OC-8/87.[ Advisory Opinion OC-8/87]. Recuperado de: https://n9.cl/ypy83

Valarezo Álvarez, M., Coronel Abarca, D., y Durán Ocampo, A. (2019). La garantía constitucional de la libertad personal y el habeas corpus como elemento de protección del bien jurídico. [ The constitutional guarantee of personal liberty and habeas corpus as an element of protection of the legal good]. Revista Universidad y Sociedad, 11(5), 470-478. Recuperado de: https://n9.cl/rxx1u 